\title{
Eight tips and questions for your bibliographic study in business and management research
}

\author{
Jörn H. Block ${ }^{1,2,3} \cdot$ Christian Fisch $^{1,2}$
}

Published online: 18 May 2020

(c) The Author(s) 2020

Management Review Quarterly (MRQ) specializes in systematic literature reviews, meta analyses, replication studies, and bibliographic studies. Previous editorials published in MRQ provide authors with guidelines for performing systematic (narrative) literature reviews (Fisch and Block 2018) and replication studies (Block and Kuckertz 2018). In this editorial, we focus on bibliographic studies and outline eight tips that help authors to improve their bibliographic studies.

In contrast to systematic literature reviews, meta analyses, and replication studies, little information on best practices and guidelines exist on bibliographic studies (also known as bibliographic literature reviews). Over the last years, we saw a steady increase in the number of bibliographic studies submitted to MRQ. We attribute this rise to the better accessibility of bibliographic data and software packages that specialize in bibliographic analyses. Another antecedent of the increasing prevalence of bibliographic studies is the ongoing differentiation of business and management research into narrowly defined subdisciplines, which calls for studies that are interdisciplinary and 'break the walls'. Well-conducted bibliographic studies can break those walls. They structure a field and detect links between disciplines, identify topic clusters, literature gaps and academic silos, and show the most impactful authors and their research. Yet, in contrast to narrative literature reviews, bibliographic literature reviews use quantitative and statistical methods to achieve this goal.

We currently observe a considerable heterogeneity in the type and quality of bibliographic studies submitted to MRQ. These submissions range from systematic narrative literature reviews erroneously labeled as bibliographic ones to

Jörn H. Block

block@uni-trier.de

Christian Fisch

cfisch@uni-trier.de

1 Faculty of Management, Trier University, 54296 Trier, Germany

2 Erasmus School of Economics, Erasmus University Rotterdam, P.O. Box 1738, 3000 DR Rotterdam, The Netherlands

3 Wittener Institut für Familienunternehmen (WIFU), Universität Witten/Herdecke, Alfred-Herrhausen-Str. 50, 58448 Witten, Germany 
purely technical citation analyses with little interpretation and discussion of the state of the art in the respective research field. Hence, there seems to be confusion in business and management research as to what a bibliographic study is and what defines its quality. The goal of this editorial is to reduce this confusion and help future authors of MRQ to craft bibliographic studies of high quality. In line with earlier MRQ editorials, we organize this editorial in eight tips and questions. Specifically, we outline suggestions that we perceive as crucial for every bibliographic study published in MRQ. Since bibliographic studies rely on a systematic collection of articles, this editorial shares many similarities with our editorial on systematic narrative literature reviews (Fisch and Block 2018) as well as as the editorial's discussion and extension by Clark et al. (2020). We summarize the main commonalities and differences of the two forms of literature reviews in Table 1.

1. Is your study really a bibliographic study? Although the term 'bibliographic study' is widely used in academic research, a clear definition is lacking. MRQ is interested in bibliographic studies, which we define as systematic literature reviews that analyze bibliographic data with bibliometric methods. Bibliographic data include, amongst others, author names, journal names, article titles, article keywords, article abstracts, and article publication years. These bibliographic data are collected and made available by bibliographic databases such as Web of Science (WoS) or Scopus. These databases also provide citation data. Bibliometric methods rely on statistical methods to analyze bibliographic and citation data. As noted above, many manuscripts submitted to MRQ are erroneously labeled as bibliographic studies as they do not use bibliometric (=statistical) methods and only provide lists of important and impactful studies, authors, topics, and journals. Compiling and providing such lists is an essential first step but does not qualify your study as a bibliographic study. Also, bibliographic studies should not be confused with annotated bibliographies, which comprise a list of references to important studies followed by a brief description of their content. MRQ sees annotated bibliographies as an important element of systematic narrative literature reviews.

2. Is your main research goal really to summarize the structure of a research field? Literature reviews can summarize the content and structure of a particular research field. While a narrative literature review aims to summarize the content of the studies of a particular research field, a bibliographic literature review focuses on assessing the structure of a particular research field. A description and summary of "simple" bibliographic data (e.g., authors, journal names) is too superficial to derive specific answers to particular research questions. Article titles, keywords, and abstracts are already more informative and can, for example, be used to identify topic clusters. Citation data helps to identify impactful articles, authors, and journals. Such data also facilitates the identification of topic clusters and allows the measurement of knowledge diffusion within and between disciplines. 


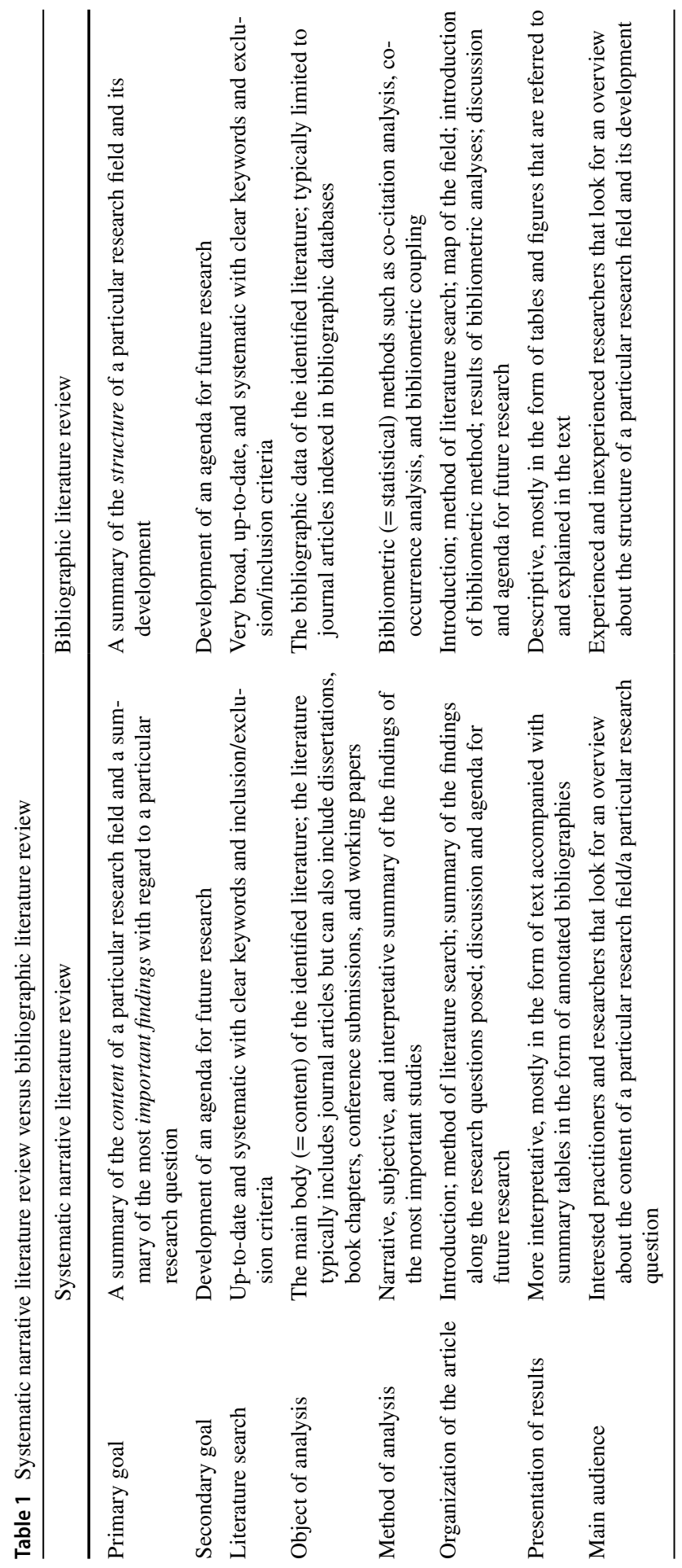


3. Provide and motivate a research goal and explain why a bibliographic study is needed to achieve this goal. Your article's abstract and introduction have an important motivational function. As such, carefully begin your study by delineating and motivating your research goal. In particular, carefully explain why you choose a bibliographic literature review to achieve this goal. In other words: inform the reader that the analysis of bibliographic data with bibliometric methods provides important insights regarding your research goal. In general, bibliographic studies are particularly useful to describe the structure of a research field (see tip 2 above) and its development over time because they help to identify topic clusters, author networks, literature gaps, and academic silos.

4. Identify the relevant literature in a broad, systematic, and reproducible way. A bibliographic study is a particular form of a systematic literature review. Hence, the literature search process should be transparent and reproducible. A detailed account of the search strategy is needed, which includes a description of the databases used, the search terms, and inclusion/exclusion criteria. ${ }^{1}$ In particular, carefully choose your bibliographic database. For example, Scopus often has a broader coverage of journals than WoS and if you leave out some of the most important journals, that's a problem. Note that the application of screening or inclusion criteria (e.g., only focusing on highly ranked journals) should be welljustified because the screening criteria can have crucial implications for the bibliographic data obtained and the results of the quantitative, bibliometric analysis that follows. Since bibliographic studies rely on a quantitative and objective approach to summarize the structure and trends of a field, the systematic approach to identifying the literature is, in our view, even more important than in interpretative and narrative forms of literature reviews. We also believe that the literature covered should be broader than in narrative literature reviews, for example, with regard to the journals or publication years considered.

5. Provide a map of the research field. While original empirical research articles typically begin their results section with descriptive statistics, bibliographic studies should commence with a description of the studies under investigation (i.e., a map of the field). For example, a good strategy is to provide a chronological view of the field (e.g., how has the number of studies evolved, how have the topics evolved, how have the outlets evolved), and to give an overview of the most influential authors, journals, and publications. The outline can be sorted by multiple criteria, such as the number of papers or different citation measures. Notice that different types of citation data exist and that you need to defend your approach and source of citation data. In our view, this map of the field is a critical part of any bibliographic study. Yet, a bibliographic study should not stop at that stage. Instead, you should use the map of the field as a starting point to dig deeper into your bibliographic data using bibliometric methods, as outlined in tip 6.

6. Clearly specify the methodological steps of your bibliometric analysis. As with most empirical and statistical analyses, performing a bibliometric analysis

\footnotetext{
${ }^{1}$ See Fisch and Block (2018) and the references cited therein for more tips on systematic literature search.
} 
requires taking various methodological choices. For example, authors need to choose a software and need to carefully prepare the data to be used in the analysis, such as the keywords of articles used. Make a sensible choice about which keywords to include in the analysis. For example, including your original search terms as keywords may produce trivial results. While a lot of graphical illustrations exist in the field of bibliographic studies (e.g., to visualize citation clusters or links between authors), sometimes tables can be easier to understand and interpret than figures (which are also often in color and difficult to print). Carefully outline and motivate the choices made in this regard.

7. Use the full potential and range of bibliometric methods. A bibliographic study should rely on statistical tools to derive results. Hence, you should go beyond simple article and citation counts. Such measures can be used to provide a map of the field (see tip 5), but the main part of the bibliometric analysis should be build on more sophisticated, multivariate statistical analyses. Bibliometric or scientometric analysis has developed into a discipline itself and specialized journals exist, such as Scientometrics and the Journal of Informetrics. Some commonly applied bibliometric methods, which we would like to also see in MRQ manuscripts, include co-citation analysis, co-occurrence analysis, and bibliometric coupling. We require authors of bibliographic studies to use such methods as a basis for their statements about the structure as well as the thematic clusters and gaps in the field. Yet, try to use these tools in a meaningful way. Simply displaying sophisticated tables, figures, and graphs derived from bibliometric software tools can lead to an overly descriptive and confusing picture of the field. Try to identify a relevant and interesting "story" that is supported by your bibliographic data and bibliometric analyses. Good examples of articles that have followed this approach are Aliyev et al. (2019), Block et al. (2019), and Kumar et al. (2019).

8. The bibliometric analysis needs to serve a purpose and needs to contribute to your research goal. The bibliometric analysis is the core of a bibliographic study. The most common mistake we see in manuscripts submitted to MRQ is that authors perform bibliometric analyses for the sake of performing bibliometric analyses. We are not interested in such manuscripts because they do not structure the knowledge in our field, do not lead to a discussion of where we are and what we know, and do not provide an agenda for future research. Hence, make sure that your bibliometric analysis contributes to the overall goal of MRQ. Like a systematic narrative literature review, bibliographic studies must go beyond a mere descriptive summary of prior literature. They require the authors to interpret and discuss the development and state of the field and give suggestions for meaningful future research.

Acknowledgements Open Access funding provided by Projekt DEAL.

Open Access This article is licensed under a Creative Commons Attribution 4.0 International License, which permits use, sharing, adaptation, distribution and reproduction in any medium or format, as long as you give appropriate credit to the original author(s) and the source, provide a link to the Creative Commons licence, and indicate if changes were made. The images or other third party material in this article are included in the article's Creative Commons licence, unless indicated otherwise in a credit line to the material. If material is not included in the article's Creative Commons licence and your intended use is 
not permitted by statutory regulation or exceeds the permitted use, you will need to obtain permission directly from the copyright holder. To view a copy of this licence, visit http://creativecommons.org/licen ses/by/4.0/.

\section{References}

Aliyev F, Urkmez T, Wagner R (2019) A comprehensive look at luxury brand marketing research from 2000 to 2016: a bibliometric study and content analysis. Manag Rev Q 69(3):233-264

Block J, Kuckertz A (2018) Seven principles of effective replication studies: strengthening the evidence base of management research. Manag Rev Q 68(4):355-359

Block J, Fisch C, Rehan F (2019) Religion and entrepreneurship: a map of the field and a bibliometric analysis. Manag Rev Q. https://doi.org/10.1007/s11301-019-00177-2 (forthcoming)

Clark WR, Clark LA, Raffo DM, Williams RI (2020) Extending Fisch and Block's (2018) tips for a systematic review in management and business literature. Manag Rev Q. https://doi.org/10.1007/s1130 1-020-00184-8 (forthcoming)

Fisch C, Block J (2018) Six tips for your (systematic) literature review in business and management research. Manag Rev Q 68(2):103-106

Kumar S, Sureka R, Colombage S (2019) Capital structure of SMEs: a systematic literature review and bibliometric analysis. Manag Rev Q. https://doi.org/10.1007/s11301-019-00175-4E (forthcoming)

Publisher's Note Springer Nature remains neutral with regard to jurisdictional claims in published maps and institutional affiliations. 